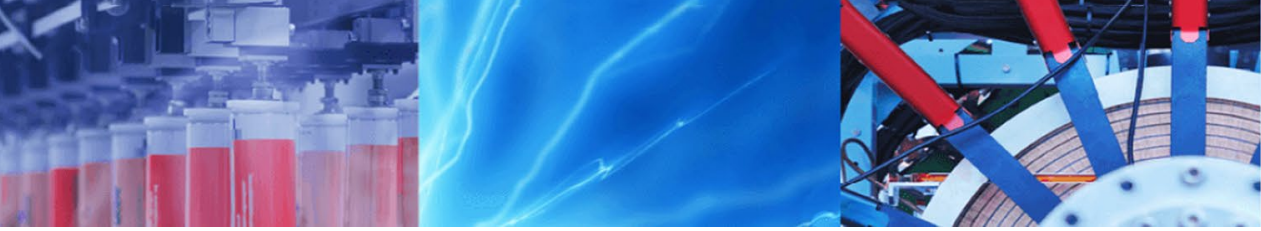

Review Paper

\title{
Compressive strength of concrete with palm kernel shell as a partial replacement for coarse aggregate
}

\author{
Sunday U. Azunna ${ }^{1}$ \\ C The Author(s) 2019 OPEN
}

\begin{abstract}
Shelter is a basic human need. Unfortunately, decent shelter for the masses; the poor have not materialized over the years. The cost of concrete materials in building and civil engineering project has been a concern to the society. These and other things led to the research on biological local materials that are dumped as waste in our environment, causing pollution and congestion as substitute materials. Therefore, this research work was carried out in respect to that and the research work was carried out to determine the use of palm kernel shell as a partial replacement for coarse aggregate in concrete taking into consideration the compressive strength and water absorption capacity. The following tests were carried out; visual test, sieve analysis, specific gravity test, slump test, water absorption test and compressive strength test. The result of water absorption and compressive strength shows that the water absorption capacity of palm kernel shell is normal compared to plain concrete and a replacement of $10 \%$ and $25 \%$ gave $4.78 \mathrm{~N} / \mathrm{mm}^{2}$ and $4.44 \mathrm{~N} / \mathrm{mm}^{2} \mathrm{com}$ pressive strengths respectively which cannot be used for light weight structure.
\end{abstract}

Keywords Palm shell · Lightweight aggregate $\cdot$ Lightweight concrete $\cdot$ Compressive strength $\cdot$ Mechanical properties

\section{Introduction}

Concrete is the most commonly used material employed for construction purpose in the world today [1], the expensive cost of concrete constituents such as cement, fine and coarse aggregate has necessitated the need to search for alternative construction materials $[1,2]$. The general importance of concrete application in construction projects and civil works cannot be overemphasized. The overwhelming demand for concrete in construction adopting normal weight aggregates (NWAs), such as gravel and sand has led to tremendous depletion in naturally occurring aggregates causing numerous damage to the environment which are irreparable [2]. As a result, the need to search for more sustainable and renewable materials has been intensified. Some waste agricultural materials such as saw dust, maize comb, rice husk, and coconut shell, palm kernel shell etc. can serve as a good substitute or admixture for some of these traditional construction materials. These local materials are in most cases dumped as waste in our environments, causing environmental pollution. Many of which can be used as lightweight aggregate (LWA) to produce light weight concrete which has the advantage of reducing the self weight of concrete structures as compared to conventional concrete which possess heavy dead load, they can also be used for purposes of structural stability and versatility as well as economic viability [3]. Hence incorporating these waste materials will help reduce the rate of exploitation of nonrenewable natural resources [4] and provide more sustainable concrete [5]. Furthermore, the idea of using raw materials as concrete constituents is capable of proffering solution to energy saving problems encountered in many agro industries [6].

An agricultural waste that has proven successful in concrete production is palm kernel shell (PKS). In the last three decades, palm kernel shell (PKS) has been used

$\triangle$ Sunday U. Azunna, usazunna@yahoo.co.uk; usazunna@gmail.com | 1 Department of Civil Engineering, Faculty of Engineering, Housing Research Center, Universiti Putra Malaysia (UPM), 43400 Serdang, Selangor, Malaysia.

SN Applied Sciences (2019) 1:342 | https://doi.org/10.1007/s42452-019-0334-6

Received: 22 January 2019 / Accepted: 3 March 2019 / Published online: 14 March 2019

SN Applied Sciences

a SPRINGer nature journal 
by scientists as LWA to substitute conventional NWA in building and road construction in Africa and Southeast Asia. One of the advantages of PKS is that it has better impact resistance compared to NWA [7]. Innumerable articles have been published on the physical, mechanical, structural and functional properties using PKS as Lightweight aggregate. PKS is extracted from the oil palm tree as a waste product [7]. It is majorly located in Eastern and Western Africa with a scientific name of Elaeis guineensis [8]. In the past, growing of palm oil tree was sequestered in the Eastern part of Africa as history records that the founding of palm oil trees dates back to the era of Pharaohs some 5000 years ago but currently, the cultivation of palm oil trees have become a major priority in some South East Asian countries such as Indonesia and Malaysia. In a report by Olanipekun et al. [9] large quantities of palm oil trees can be located in Asia, America and some part of Africa specifically Nigeria. The total production of palm oil in Malaysia alone is $52.8 \%$ and about $90 \%$ of the world's palm oil exportation comes from Malaysia and Indonesia [8]. The palm oil nut contains two kinds of oil; one is palm oil which is extracted from the fleshy and oily layer called the mesocarp and the other is palm kernel oil which is extracted from the inner core, known as palm kernel (endosperm). A endocarp layer which envelops the Palm kernel is called palm kernel shell $[8,9]$.

Over 4 million tons of PKS are produced by Malaysia annually $[7,10]$ and from Ramli [11] investigation a total of 5 million hectare (ha) palm oil trees are expected by the year 2020. By virtue of its position as the second largest palm oil producing country in the world, it is expected that huge amount of palm kernel shell wastes will be found in Malaysia. As part of measures to facilitate and enhance the preservation of the environment, scientists have decided to look into the resourcefulness of PKS as LWA $[3,12,13]$. Proposals were made to alternatively use PKS as road based materials rather than asphalt on numerous accounts $[9,13,14]$. In an investigation by Teo et al. [13, 15] PKS was employed as LWA to construct a building with one suspended floor and a foot bridge and the structural behavior were closely monitored on both accounts. PKS is also used as granular filter material for water treatment $[9,16]$, road based material and floor roofing [13]. Okpala [7] observed the heat conductivity of $0.19 \mathrm{Wm}^{-1} \mathrm{~K}^{-1}$ for PKS which is much lower than the value of $1.4 \mathrm{Wm}^{-1} \mathrm{~K}^{-1}$ for normal coarse aggregate. Hence a more conducive environment and low energy usage can be achieved with lightweight concrete made with PKS as a result of the high insulation capacity and low thermal conductivity. In recent times, experiments have been made to substitute PKS as a replica for poor lateritic soil. But the data analysis indicates that the composite mix of PKS with asphalt is insufficient for sub-grade, sub-base and base course in highway construction [17].

Mohamed et al. [18] investigated the proportioning of mixture for oil palm kernel shell lightweight concrete with batch of 1:1.6:0.96 and 1:1.53:0.99 for C:S:OPKS ratio with cement content of $450 \mathrm{~kg} / \mathrm{m}^{3}$ which yielded minimum slump of $20 \mathrm{~mm}$, density within the range of 1800 and $1900 \mathrm{~kg} / \mathrm{m}^{3}$ and minimum compressive strength of $15 \mathrm{~N} / \mathrm{mm}^{2}$. Yusuf et al. [19] carried out an experiment on the structural application of lightweight concrete incorporated with palm kernel shells adopting a mix ratio of $1: 1: 2$ and $w / c$ of 0.5 . PKSC beam at 28 days showed flexural strength of $2.883 \mathrm{~N} / \mathrm{mm}^{2}$ and deflection of $0.947 \mathrm{~mm}$ indicating resistance to load of $3981 \mathrm{~N}$. Elnaz et al. [20] tried to compare the effects of cockle and palm kernel shell on pervious concrete pavement. In this research thirteen different mixes where prepared employing $6.3 \mathrm{~mm}$ size natural gravel and substituted it at different percentage with $4.75 \mathrm{~mm}$ and $6.3 \mathrm{~mm}$ CS and PKS respectively. Replacement of natural gravel by CS and PKS showed decrease in compressive strength but recorded strong relationship values between the mechanical and durability properties. The compressive strength value indicates that it can be used as quality control tests to foretell the field properties of pervious concrete pavement upon application. Mohammad et al. [21] replaced nominal concrete constituents with agricultural solid wastes of oil palm shell (OPS) and oil palm fuel ash (OPFA) at $10-15 \%$ in a bid to produce a sustainable OPS lightweight concrete of enhance mechanical properties. Increase in percentage addition of POFA led to subsequent decrease in flexural and split tensile strengths of OPSC but gave optimum sustainability performance at $10 \%$. Elnaz et al. [22] developed an economical lightweight pervious concrete by replacing gravel sized 6.3-9.5 $\mathrm{mm}$ with palm kernel shell (PKS) sized 4.75-6.3 $\mathrm{mm}$ and $6.3-9.5 \mathrm{~mm}$. In the same manner PKS was used to replace limestone from 25 to $75 \%$ to reduce cost. Results showed maximum compressive of $12 \mathrm{~N} / \mathrm{mm}^{2}$ and higher permeability values ranging from 4 to $6 \mathrm{~mm} / \mathrm{s}$ which can be applied in parking lots and roads of light traffic. Oyedepo et al. [23] evaluated the performance of both coconut and palm kernel shells ash (CSA and PKSA) as cement replacements in concrete, adopting mix proportion of 1:2:4 and $\mathrm{w} / \mathrm{c}$ of 0.63 . Maximum compressive strengths of $15.4 \mathrm{~N} / \mathrm{mm}^{2}$ and $17.26 \mathrm{~N} / \mathrm{mm}^{2}$ was achieved at $20 \%$ cement replacement with PKSA and CSA while $10 \%$ cement substitution with CSA gave a compressive strength of $20.58 \mathrm{~N} / \mathrm{mm}^{2}$ at 28 days. The mechanical properties show that it is suitable for both heavy and lightweight concrete. Okechukwu et al. [24] tested the effect of palm kernel shell aggregate as partial replacement for coarse aggregate 
on the physical properties of concrete. At the age of 28 the concrete cubes yielded compressive strengths and densities ranging from $12.71-16.63 \mathrm{~N} / \mathrm{mm}^{2}$ to 1562 to $2042 \mathrm{~kg} / \mathrm{m}^{3}$ respectively. Water absorption results at 6 , 11 and $21.5 \%$ were observed to be $1 \mathrm{~h}$ and $24 \mathrm{~h}, 1 \mathrm{~h}$, $24 \mathrm{~h}$ respectively.

The properties of palm kernel shell lightweight concrete (PKSC) and normal weight concrete (NWC) have been compared both mechanically and structurally by a lot of observers to show the efficacy of PKSC $[3,10$, 15]. Physical and mechanical properties, and structural behavior with regards to bond, flexure and shear, have been experimented and reported [10, 25]. Durability properties of PKSC such as creep [25] and shrinkage $[12,25]$ were also compared with NWC. Achieving the minimum concrete grade requirement as well as specify areas where PKSC can be used will promote the application of palm kernel shell in many civil works thereby eradicating the biological and environmental hazards caused as a result of improper disposal of the palm kernel shells and reduce cost of construction. Palm kernel shells could be employed for construction purposes in rural villages where they are easily accessible and places where natural occurring aggregates are expensive. In this paper, the engineering properties of concrete made with varying percentage of palm kernel shells as aggregate is determined. This research will aim to evaluate the performance characteristics of palm kernel shell at different percentage replacements for coarse aggregate to determine the specific civil engineering areas where when the PKSC are applied will perform efficiently. Concrete mix design of 1:2:4 was used for the experiment and the following test were conducted to achieve the above mentioned objectives; Water absorption capacity of both aggregate and concrete; specific gravity of sand, particle size distribution of sand and palm kernel shell, workability of concrete and the compressive strength of the concrete. The values of this test results obtained were compared with normal sample made with normal aggregate.

\section{Experimental programme}

\subsection{Materials}

\subsubsection{Cement}

Ashaka brand of ordinary Portland cement (OPC) was used for the test as a binder as it complies to the requirement in BS EN 197-1 [26], composition, specification and conformity criteria for a common cement.

\subsubsection{Coarse aggregate}

The coarse aggregate (Gravels) used for the experiment were obtained from the Civil Engineering Department, Federal Polytechnic Bauchi; Materials stock pile. The grading of the gravel are those that pass through $14 \mathrm{~mm}$ sieve size and but retained on $10 \mathrm{~mm}$ sieve. The gravels were properly washed and dried under the sun for 3 days, to remove impurities and any absorbed water.

\subsubsection{Fine aggregate}

Fine aggregate (fine sand also known as river sand was equally used for the experiment). The sand was sun dried and impurities removed using $5 \mathrm{~mm}$ sieve in which materials retained on the sieve were discarded.

\subsubsection{Palm kernel shell aggregate}

The major material for the experiment conduct is the Palm kernel shell was obtained from Sri kembangan market in Malaysia and from Benue State, Cross River, middle and south eastern part of Nigeria. A total weight of $100 \mathrm{~kg}$ of this material was brought for the practical. The palm kernel shell source was washed to remove fibers and foreign impurities after which it was sun dried for three days to eliminate water and any microbial activity on the shell surface (Fig. 1).

\subsubsection{Water}

This is an important material which was used for the practical mostly conducted. The source of the water is Civil Engineering Department, Federal Polytechnic Bauchi Tap by visual inspection; the water was clean, odorless, and fit the practical with no significant effect.

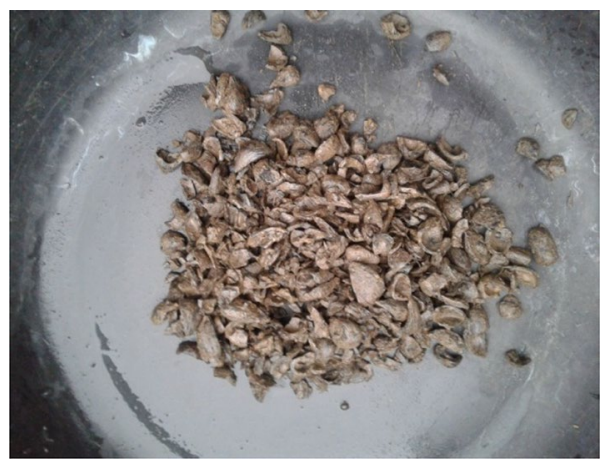

Fig. 1 Samples of palm kernel shells 


\subsubsection{Compressive strength test}

This compressive strength test was carried out according to BS EN 12390-4 [27] filling 150 mm cube mould with concrete in three layers of approximately $50 \mathrm{~mm}$ with each layer receiving 25 blows for proper compaction. The mix ratio was 1:2:4 with the coarse aggregate being at $100 \%$ gravel and replaced by palm kernel shell at 10, 25, 50, 75, and $100 \%$. The concrete cubes were demoulded after $24 \mathrm{~h}$ and taking for curing at the curing tank with water temperature of $20^{\circ} \mathrm{C}$ the cube were left in the tank until the prescribed age ranging from 7, 14, 21, and 28 days was reached. After removal from the curing tank, the cubes were weight and tested for strength with their cast faces in contact with the plate of the compression machine. The load was then applied at a constant rate of stress within the range of $0.02-0.4 \mathrm{~N} / \mathrm{mm}^{2}$ and crushing strength was reported to the nearest $0.05 \mathrm{~N} / \mathrm{mm}^{2}$.

\subsubsection{Water absorption capacity of the concrete}

After demoulding, the concrete cube was immersed in water to test for the total amount of water they can absorb and the results were reported. Gunasekeran [28] observed that when concrete cubes are cured for a long period of the incidence of cracking is reduced.

\subsubsection{Batching}

Being that the process of measuring the quantities of each material i.e. cement, fine and coarse aggregate and water in their relative proportion before they are mixed is known as batching. And there are two methods of this batching; by weight and by volume. This research adopted batching by weight, which involves the application of mathematical concept known as ratio to find out the requirement weight. Weight was used for the measurement.

\subsubsection{Batching calculation}

The volume of cement, sand, coarse aggregate and palm kernel shell, water base on the ratio of normal 1:2:4 mix (Table 1).

Cement $=\frac{1 \times 1440}{3.15}=0.457 \mathrm{~m}^{3}$

Sand $=\frac{2 \times 1650}{3.15}=1.269 \mathrm{~m}^{3}$

Coarse aggregate $=\frac{4 \times 1600}{2.65}=2.415 \mathrm{~m}^{3}$

\section{Results and discussions}

\subsection{Specific gravity of fine sand}

Test conducted in accordance to BS EN 1097-3 [29] gives the specific gravity of fine aggregate as shown in the Table 2:

$G_{s}=\frac{W_{2}-W_{1}}{\left(W_{4}-W_{1}\right)-\left(W_{3}-W_{2}\right)}$

specific gravity of the fine sand is 2.67 .

Specific gravity of PKS varies from but has never exceeded the value of 2.0 as observed by several scientists $[7,15,30]$, the value ranges from 1.17-1.62. Ndoke [30] recorded the highest value of PKS specific gravity

Table 2 Fine sand specific gravity result

\begin{tabular}{lll}
\hline Mass of apparatus & Weight & Weight (g) \\
\hline Mass of density bottle & $\mathrm{W}_{1}$ & 29.72 \\
Mass of bottle + dry sand & $\mathrm{W}_{2}$ & 40.97 \\
Mass of bottle dry sand + water & $\mathrm{W}_{3}$ & 86.30 \\
Mass of bottle + water & $\mathrm{W}_{4}$ & 79.25 \\
\hline
\end{tabular}

Table 1 Mix proportion for 1:2:4 concrete mix

\begin{tabular}{lllllll}
\hline Mix design (\%) & $\begin{array}{l}\text { Concrete } \\
\text { volume }\left(\mathrm{m}^{3}\right)\end{array}$ & Cement $(\mathrm{kg})$ & Water $(\mathrm{kg})$ & FA $(\mathrm{kg})$ & CA $(\mathrm{kg})$ & PKSA $(\mathrm{kg})$ \\
\hline 0 & 0.003375 & 18.4842 & 9.24 & 42.357 & 82.15 & 0 \\
10 & 0.003375 & 18.4842 & 9.24 & 42.357 & 73.90 & 08.20 \\
25 & 0.003375 & 18.4842 & 9.24 & 42.357 & 61.61 & 20.54 \\
50 & 0.003375 & 18.4842 & 9.24 & 42.357 & 41.07 & 41.07 \\
75 & 0.003375 & 18.4842 & 9.24 & 42.357 & 20.54 & 61.61 \\
100 & 0.003375 & 18.4842 & 9.24 & 42.357 & 0 & 82.15 \\
\hline
\end{tabular}


1.62 in a research where PKS was used for soil stabilization. On the other hand Okpala [7] recorded the lowest value of specific gravity of 1.14, while Teo et al. [15], Mannan and Ganapathy [31], and Basri et al. [13] recorded equal values of 1.17 . This can be compared to the specific gravity NWA of 2.67 reported above. Other artificial LWA such as LECA and Lytag and natural LWA such as pumice and expanded shale all poses specific gravity values ranging from $0.8-0.9$ to $1.30-1.7$, respectively [32].

\subsection{Sieve analysis results}

\subsubsection{Sieve analysis for fine aggregate}

This gives the particle size distribution of the fine sand sample, as shown in Table 3.

For the fine aggregate (sand), the $\mathrm{C}_{\mathrm{u}}$ and $\mathrm{C}_{\mathrm{c}}$ are calculated below in accordance to BS 812-103.1 [33]

Uniformity of curvature $C_{c}=\frac{\left(D_{30}\right)^{2}}{D_{10} \times D_{60}}$

Uniformity coefficient $C_{u}=\frac{D_{60}}{D_{10}}$

From the Fig. 2

$$
\begin{aligned}
& C_{u}=4.26 \times 10^{9} \\
& C_{c}=6.863 \times 10^{-1}
\end{aligned}
$$

From the result obtained; $C_{u}$ and $C_{c}$ of the particle size distribution of the fine aggregate is suitable for construction.

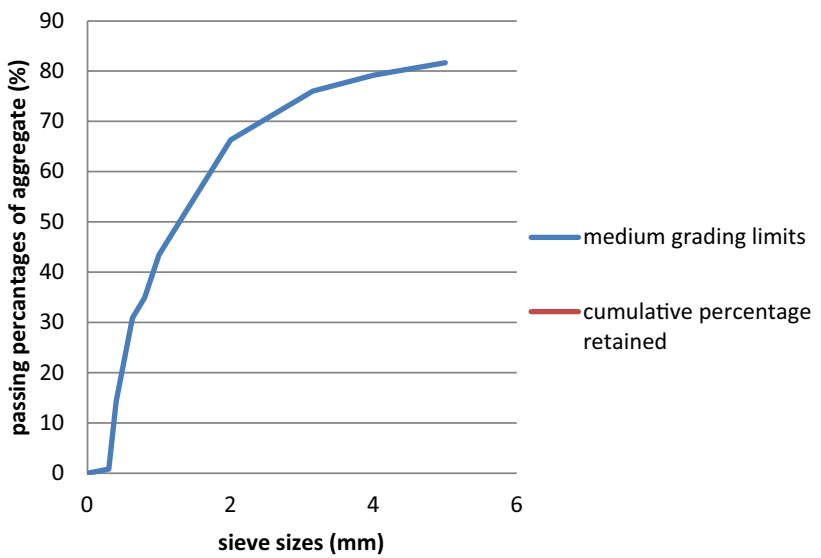

Fig. 2 Grading curve for fine aggregate

\subsection{Sieve analysis for palm kernel shell}

This give the particle size distribution of the palm kennel shell used as a substitute material for the concrete. Shown in Table 4.

According to Table 4 and Fig. 3, the passing percentage lies within the range of medium grading limit to be used in the mix design making it suitable for construction.

\subsection{Moisture content of palm kernel shell}

This gives the moisture content present in the material (palm kennel shell) as shown in Table 5.

Average weight of wet sample $=7.48 \mathrm{~g}$

Average weight of dry sample $=7.28 \mathrm{~g}$

$$
\begin{aligned}
\text { Moisture content } & =\frac{\text { Wet weight }- \text { Dry weight }}{\text { Dry weight }} \times 100 \\
& =2.7 \%
\end{aligned}
$$

Table 3 Sieve analysis for fine aggregate

\begin{tabular}{lccc}
\hline Bs sieves $(\mathrm{mm})$ & $\begin{array}{l}\text { Mass retained } \\
\text { on sieve }\end{array}$ & $\begin{array}{l}\text { Mass passing } \\
\text { on sieve }\end{array}$ & \% Passing sieve \\
\hline 5.0 & 22.62 & 408.86 & 81.7 \\
4.0 & 12.62 & 390.18 & 79.2 \\
3.15 & 15.73 & 380.45 & 76.0 \\
2.0 & 48.85 & 331.60 & 66.3 \\
1.0 & 113.83 & 217.78 & 43.5 \\
0.800 & 43.04 & 174.74 & 34.9 \\
0.630 & 19.94 & 154.50 & 30.9 \\
0.400 & 80.60 & 74.11 & 14.3 \\
0.300 & 69.9 & 4.20 & 0.84 \\
Pan & 4.20 & 6.00 & 0.0 \\
Total & & & \\
\hline
\end{tabular}

Table 4 Sieve analysis for palm kernel shell

\begin{tabular}{lccc}
\hline Bs. sieve & $\begin{array}{l}\text { Mass retained } \\
\text { on sieve }(\mathrm{g})\end{array}$ & $\begin{array}{l}\text { Mass passing on } \\
\text { sieve }(\mathrm{g})\end{array}$ & \% passing sieve \\
\hline 25 & 0.01 & 2273.72 & 22.73 \\
20 & 1.07 & 2273.65 & 22.73 \\
16 & 19.63 & 2253.02 & 22.53 \\
12 & 651.06 & 1001.96 & 16.01 \\
10 & 607.41 & 525.41 & 0.73 \\
8 & 469.14 & 525.41 & 0.52 \\
Pan & 525.41 & 0.000 & 0.000 \\
\hline
\end{tabular}




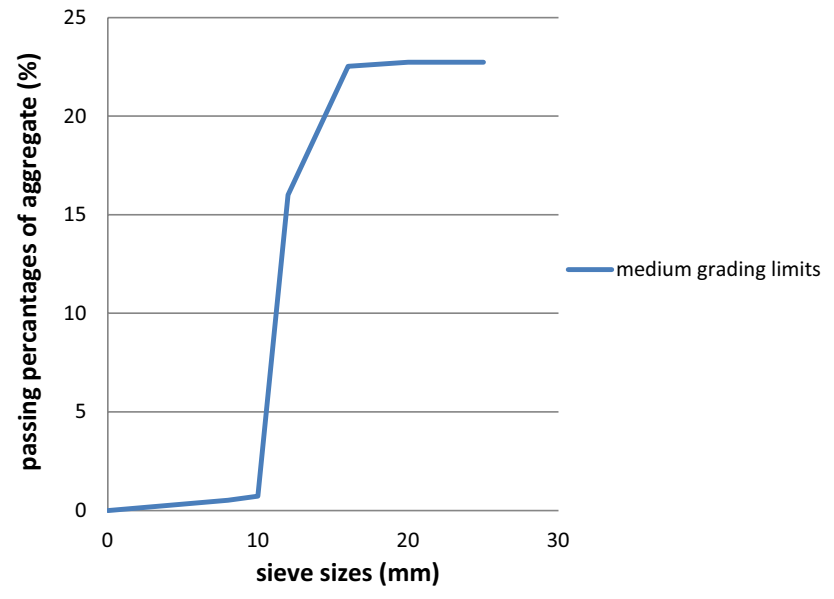

Fig. 3 Grading curve for palm kernel shell coarse aggregate

The moisture content of the palm kernel shell is $2.7 \%$ which has no much effect to the concrete per $100 \%$ moisture BS EN 1097-3 [29].

\subsection{Water absorption capacity}

This gives the maximum water absorbed by the palm kernel shell after eight days as shown in the Table 6 .

The maximum water absorbed by the palm kernel shell $=0.66 / 5.48=12.0 \%$

Water absorption is defined as the transport of liquids in porous solids caused by surface tension acting in the capillaries [34]. From the result obtained, the maximum amount of water absorbed by the palm kennel shell shows that the absorption capacity of the material is higher than that of the normal coarse aggregate [17].

Water absorption of NWA is typically found to be in the range of $0.5-1 \%$ [35]. As a result of higher water absorption of PKS compared to NWA, the mix design differs from that of the conventional mix design of NWC or LWC $[35,36]$. In a report by Gunasekaran et al. [37] coconut shell aggregate posses water absorption of $24 \%$ which is very similar to that of palm kernel shell aggregate. Due to the fact that PKS is an organic aggregate, its pore content is high resulting in high water absorption. The $24 \mathrm{~h}$ PKS water absorption varies in the range of $14-33 \%$ as it is dependent on the maturity as well as the species of the tree $[7,15,30]$. Regardless of the fact that PKS posses high water absorption, much higher water absorption of $37 \%$ was reported for pumice aggregate [38]. Alengaram et al. [39] observed that with varying PKS sizes, water absorption also varies in the range of $8-15 \%$ and $21-25 \%$ for $1 \mathrm{~h}$ and $24 \mathrm{~h}$, respectively.

\subsection{Water absorption capacity of the casted cubes}

This gives the water absorption capacity of each cube casted at the different percentages of replacement, as shown in Table 7:

From the result obtained, the water absorption capacity of both the palm kernel shell used as concrete compared with the normal concrete used as control is a bit higher in the absorption capacity as such, the absorption capacity of the material is within the range for construction purpose (Table 8).

\subsection{Slump test (workability test)}

Table 9 shows the result of slump test carried out on the sample used in the concrete.

Slump test measures the degree of consistency of fresh concrete before setting according to $\mathrm{ACl} 116 \mathrm{R}$ [40]. It is very useful in calculating and checking the
Table 5 Moisture content result (PKS)

Table 6 Water absorption capacity of palm kernel shell

\begin{tabular}{llllc}
\hline $\begin{array}{l}\text { Number of con- } \\
\text { tainer }(\mathrm{g})\end{array}$ & $\begin{array}{l}\text { Weight of empty } \\
\text { container }(\mathrm{g})\end{array}$ & $\begin{array}{l}\text { Weight of sample plus } \\
\text { container }(\mathrm{g})\end{array}$ & $\begin{array}{l}\text { Oven dry sample plus } \\
\text { container }(\mathrm{g})\end{array}$ & $\begin{array}{l}\text { Weight of dry } \\
\text { sample only }\end{array}$ \\
\hline 100 & 15.04 & 22.82 & 22.64 & 7.6 \\
125 & 14.67 & 22.11 & 21.94 & 7.27 \\
175 & 15.05 & 22.19 & 22.01 & 6.96 \\
Total & 14.92 & 22.4 & 22.2 & 21.83 \\
\hline
\end{tabular}

\begin{tabular}{lllll}
\hline Sample & $\begin{array}{l}\text { Weight of concrete before } \\
\text { immersion }(\mathrm{kg})\end{array}$ & $\begin{array}{l}\text { Weight of concrete after } \\
\text { immersion }(\mathrm{kg})\end{array}$ & $\begin{array}{l}\text { Absorption } \\
\text { gain }(\mathrm{kg})\end{array}$ & \% gain of water \\
\hline A & 5.13 & 6.18 & 1.05 & 20.47 \\
B & 5.11 & 8.86 & 0.75 & 14.68 \\
C & 6.19 & 7.38 & 1.19 & 19.23 \\
Average & 5.48 & 6.14 & 1.0 & 18.13 \\
\hline
\end{tabular}


Table 7 Water absorption capacity of the casted concrete at different percentage replacement after 3 days curing

\begin{tabular}{lllllll}
\hline Cube no. & $\begin{array}{l}\text { \% Replacement of } \\
\text { coarse aggregate }\end{array}$ & $\begin{array}{l}\text { Weight before } \\
\text { immersion }(\mathrm{kg})\end{array}$ & $\begin{array}{l}\text { Weight after } \\
\text { immersion } \\
(\mathrm{kg})\end{array}$ & $\begin{array}{l}\text { Absorp- } \\
\text { tion gain } \\
(\mathrm{kg})\end{array}$ & $\begin{array}{l}\text { \% Gain in } \\
\text { moisture }\end{array}$ & $\begin{array}{l}\text { Average \% } \\
\text { gain in mois- } \\
\text { ture }\end{array}$ \\
\hline $\mathrm{A}_{11}$ & $10 \%$ & 7.2 & 7.5 & 0.3 & 4.17 & 3.48 \\
$\mathrm{~A}_{12}$ & & 7.2 & 7.4 & 0.2 & 2.78 & \\
$\mathrm{~B}_{11}$ & $25 \%$ & 6.5 & 6.7 & 0.2 & 3.08 & 3.06 \\
$\mathrm{~B}_{21}$ & & 6.6 & 6.8 & 0.2 & 3.03 & \\
$\mathrm{C}_{11}$ & $50 \%$ & 5.7 & 5.9 & 0.2 & 3.51 & 3.48 \\
$\mathrm{C}_{21}$ & & 5.8 & 6.0 & 0.2 & 3.45 & \\
$\mathrm{D}_{11}$ & $75 \%$ & 5.1 & 5.3 & 0.2 & 3.92 & 3.89 \\
$\mathrm{D}_{21}$ & & 5.2 & 5.4 & 0.2 & 3.85 & \\
$\mathrm{E}_{11}$ & $100 \%$ & 4.1 & 4.3 & 0.2 & 4.88 & 4.88 \\
$\mathrm{E}_{21}$ & & 4.1 & 4.3 & 0.2 & 4.88 & \\
\hline
\end{tabular}

Table 8 Water absorption capacity for the plain concrete used as control

\begin{tabular}{llllll}
\hline Cube no. & $\begin{array}{l}\text { Weight } \\
\text { before } \\
\text { immersion } \\
(\mathrm{kg})\end{array}$ & $\begin{array}{l}\text { Weight } \\
\text { after } \\
\text { immersion } \\
(\mathrm{kg})\end{array}$ & $\begin{array}{l}\text { Absorp- } \\
\text { tion gain } \\
(\mathrm{kg})\end{array}$ & $\begin{array}{l}\text { \% Gain in } \\
\text { moisture }\end{array}$ & \\
\hline $\mathrm{F}_{1}$ & 7.90 & 8.20 & 0.3 & $3.8 \%$ & $3.14 \%$ \\
$\mathrm{~F}_{2}$ & 8.10 & 3.30 & 0.2 & $2.47 \%$ & \\
\hline
\end{tabular}

Table 9 Result of slump test at varying \% of palm kernel shell used in the concrete

\begin{tabular}{lll}
\hline$\%$ Replacement of PKS & Slump $(\mathrm{mm})$ & Slump type \\
\hline 10 & 20 & True slump \\
25 & 30 & True slump \\
50 & 30 & True slump \\
75 & 40 & Shear slump \\
100 & 50 & Shear slump \\
\hline
\end{tabular}

uniformity of batch improperly mixed [35]. Table 2 shows that the 10,25 , and $50 \%$ replacements of coarse aggregate falls within the medium range slump which gave a true slump while, $75 \%$ and $100 \%$ complete replacement result is harsh which gave a shear slump. Mannan and Ganapathy [31] recorded very low slump (0-4 $\mathrm{mm}$ ) meaning very low workability [41]. Lightweight concrete of $15 \mathrm{~N} / \mathrm{mm}^{2}$ gave slump in the range of $0-260 \mathrm{~mm}$ [25]. It can be said that concrete with low slump doesn't necessarily denote high compressive strength [12,31]; It was observed that slump value of $105 \mathrm{~mm}$ (high workability) was achieved with incorporation of small percentage of super plasticizer [35].
Table 10 Density of concrete cubes $\left(\mathrm{kg} / \mathrm{m}^{3}\right)$

\begin{tabular}{lllll}
\hline PKS coarse agg. & \multicolumn{4}{l}{ Age (days) } \\
\cline { 2 - 5 } Replacement (\%) & 7 & 14 & 21 & 28 \\
\hline 0 & 2326 & 2311 & 2400 & 2429 \\
10 & 2193 & 2252 & 2178 & 2311 \\
25 & 1956 & 2104 & 2104 & 2222 \\
50 & 1719 & 1629 & 1659 & 1636 \\
75 & 1541 & 1529 & 1541 & 1481 \\
100 & 1363 & 1378 & 1393 & 1425 \\
\hline
\end{tabular}

\subsection{Density}

The density of concrete is based on the specific gravity of the aggregate and the properties of the other components of concrete. Density of concrete can affect the dead load of a structure. A total of 40 cubes were produced and the densities were evaluated at 7 days, 14 days, 21 days and 28 days. Average density of concrete cubes is summarized in Table 10.

Density of concrete is a determinant factor as regards to the compressive strength of concrete and is a vital variable in design of structural elements. Table 10 indicates maximum and minimum concrete densities of $2429 \mathrm{~kg} / \mathrm{m}^{3}$ and $1363 \mathrm{~kg} / \mathrm{m}^{3}$ at $0 \%$ and $100 \%$ PKS replacement respectively. Figure 4 shows corresponding decrease in the density of the concrete mix as replacement of palm kernel shell increased. However, 28-days air-dry densities of $25 \%$ PKS concrete of the typical mixes are within the range of structural lightweight concrete of density less than $2000 \mathrm{~kg} /$ $\mathrm{m}^{3}$ [41]. For purposes of construction, reduced concrete density considerably reduces the self-weight of a structure and permits easy handling of large size precast structural units. Clarke [42] observed the density of SLWC ranges between 1200 and $2000 \mathrm{~kg} / \mathrm{m}^{3}$ while Neville [35] noticed the density values between 350 and $1850 \mathrm{~kg} / \mathrm{m}^{3}$ for LWC. 


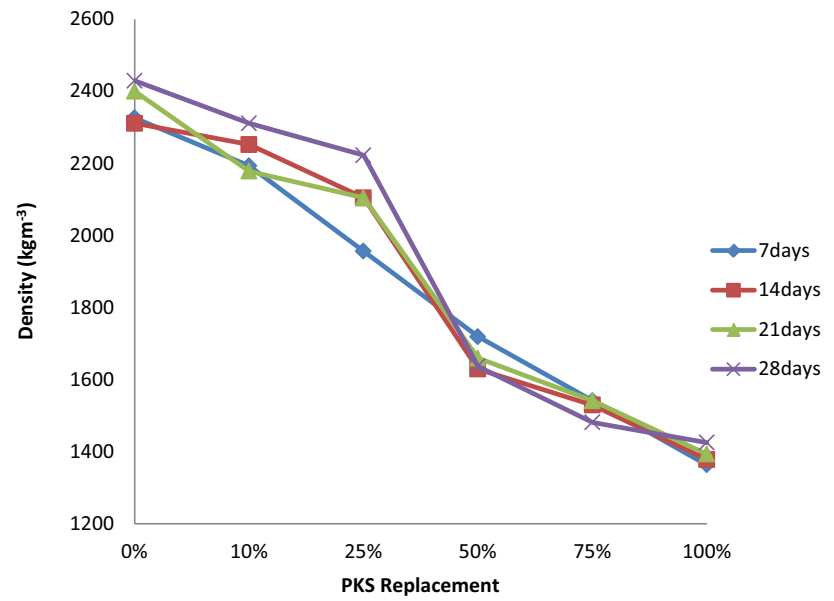

Fig. 4 Variation of density with palm kernel shell content

A number of scientists have tried to alter the density of PKSC without negatively affecting the concrete strength. The density of PKSC is dependent on a number of factors including the specific gravity of PKS, water cement $(\mathrm{w} / \mathrm{c})$ ratio, sand and PKS contents and water absorption capacity of PKS. Oven-dry densities are $200-250 \mathrm{~kg} / \mathrm{m}^{3}$ lower than the saturated surface dry (SSD) densities [42].

\subsection{Compressive strength}

Compression cube test is used to determine the mechanical strength of concrete to sustain the axial force applied on the surface of concrete. Compressive strength is the major parameter which influences other properties of concrete such as flexural strength, splitting tensile strength and modulus of elasticity. To evaluate the effect of replacement of palm kernel shell as coarse aggregates on the compressive strength of concrete plain control concrete is compared with five concrete batch mixes containing different percentage of palm kernel shell aggregates (PKSA).

The average compression strength for all batches is summarized in Table 11. The data also has been plotted and presented in Fig. 5.

In general, the compressive strength of all mixes increased steadily with respect to curing age. At 28 days, compressive strength of concrete specimen with natural fine and coarse aggregate (control specimen) was $13.22 \mathrm{~N} /$ $\mathrm{mm}^{2}$. On the other hand, the compressive strength test shows an increment in the compressive strength of the cube as the day's increases with 28 days recording, the highest value of $4.78 \mathrm{~N} / \mathrm{mm}^{2}$ and $4.44 \mathrm{~N} / \mathrm{mm}^{2}$ for $10 \%$ and $25 \%$ replacement of coarse aggregate respectively. While that of 50,75 and $100 \%$ were very low compared to the former results. The progressive increase in compressive strength shows that the palm kernel shell aggregate
Table 11 Compressive strength of concrete with PKS replacement $\left(\mathrm{N} / \mathrm{mm}^{2}\right)$

\begin{tabular}{|c|c|c|c|c|}
\hline \multirow{2}{*}{$\begin{array}{l}\text { PKS coarse agg. } \\
\text { Replacement (\%) }\end{array}$} & \multicolumn{4}{|c|}{ Age (days) } \\
\hline & 7 & 14 & 21 & 28 \\
\hline 0 & 9.45 & 10.11 & 11.05 & 13.22 \\
\hline 10 & 3.20 & 3.40 & 3.56 & 4.78 \\
\hline 25 & 2.00 & 2.33 & 2.77 & 4.44 \\
\hline 50 & 0.60 & 0.67 & 1.00 & 1.67 \\
\hline 75 & 0.40 & 0.56 & 0.89 & 1.11 \\
\hline 100 & 0.00 & 0.00 & 0.00 & 0.00 \\
\hline
\end{tabular}

doesn't undergo deterioration once the shells have been imbedded in concrete.

From Fig. 2; PKS mix compositions poses compressive strengths lower than that of the control sample. As a matter of fact, the compressive strengths at each age decreased with increase in percentages of PKS replacement.

As reported by Amarnath and Ramachandrudu [43], bond between particles is to a large extent dependent on surface texture, cement paste bonds more adequately with rough surface. However, smooth surface on the interior part of the PKS aggregate in addition to the continuous presence of water will deter adhesive bonding between the aggregate, which leads to reduction in the bonding strength. Surface area of contact between the palm kernel shells is increased as the percentage of palm kernel replacement increases, thereby requiring more cement for proper bonding. Since the content of cement in the concrete remained constant, the needed extra bonding was lacking leading to reduction in compressive strength. Furthermore, reduced compressive strength can also be attributed to the mechanical properties of coarse aggregate, since palm kernel shells are weaker in weight than granite, a reduction in the quantity of coarse aggregate

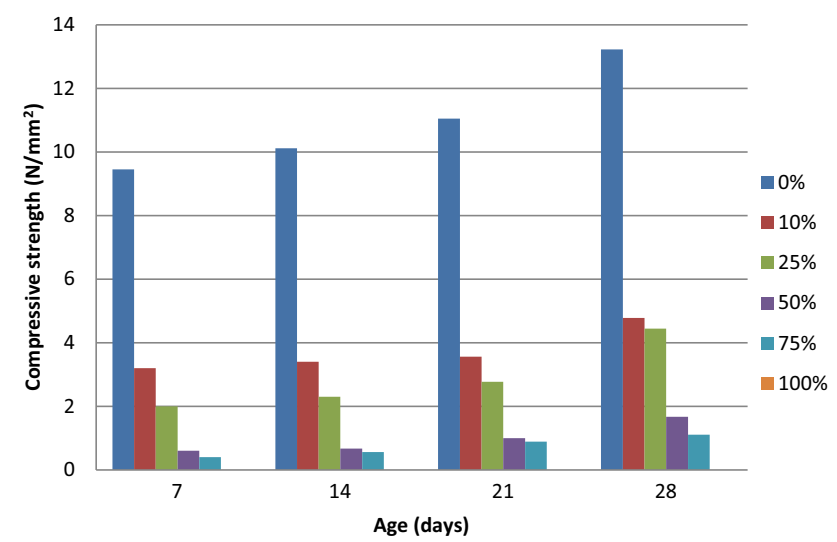

Fig. 5 Development of strength with age 
and continual increase of palm kernel shell in the concrete mix led to reduce of compressive strength [44].

Abdullah $[14,25]$ pioneered the use PKS as LWA and recorded a compressive strength of $20 \mathrm{MPa}$ with $\mathrm{w} / \mathrm{c}$ ratio of 0.4 . This value is very close to the specified cylindrical compressive (fc) strength of $17 \mathrm{MPa}$ by ACl. Teo et al. [15] reported a compressive strength of $22 \mathrm{MPa}$. Mannan and Ganapthay $[13,26]$ adopted the $\mathrm{ACl}$ method of mixed design for NWC, in their report the compressive strength was $13.65 \mathrm{MPa}$ and was surpassed by the target strength by $28 \mathrm{MPa}$. Alengaram et al. [45] reported strength of $37 \mathrm{MPa}$ which exceeded the minimum strength of $20 \mathrm{MPa}$ by $85 \%$. Silica fume and class F fly ash was employed to improve the early and later age strengths and sulfonated naphthalene formaldehyde condensate as superplasticizer to disperse the cement grains effectively, reported that the suction of silica fume into the pores of PKS promoted the bond between cement matrix and PKS.

\section{Conclusion}

In general, palm kernel shell has a good potential as a coarse aggregate in making a light weight structures and can even be used for low to moderate strength application. Base on this investigations, the following conclusions were being drawn:

- The compressive strength of the concrete for the $100 \%$ and $25 \%$ replacement are $4.78 \mathrm{~N} / \mathrm{mm}^{2}$ and $4.44 \mathrm{~N} / \mathrm{mm}^{2}$ respectively, at an age of 28 days, which did not satisfies the requirement for structural light weight concrete.

- The water absorption capacity obtained for the concrete is within the range of specification for normal concrete.

\subsection{Recommendations}

From the result obtained, palm kernel shell is recommended to be used as a partial replacement of coarse aggregate (substitute material) in making a light weight concrete. The recommended percentage replacement for possible use in construction should not be more than $25 \%$. because of its high resistant to both impact and crushing load, palm kennel shell can be used in the construction of foot path, German floor, and for self weight structures use for aesthetics purposes.

The uses of other mix ratios are recommended for further research and findings, introduction of additives, improvement of the concrete work ability and batching is also recommended to be carried out by volume.

\section{Compliance with ethical standards}

Conflict of interest The authors declare that they have no conflict of interest.

Open Access This article is distributed under the terms of the Creative Commons Attribution 4.0 International License (http://creativeco mmons.org/licenses/by/4.0/), which permits unrestricted use, distribution, and reproduction in any medium, provided you give appropriate credit to the original author(s) and the source, provide a link to the Creative Commons license, and indicate if changes were made.

\section{References}

1. Mefteh O, Kebaïli H, Oucief L, Berredjem NA (2013) Influence of moisture conditioning of recycled aggregates on the properties of fresh and hardened concrete. J Clean Prod 54:282-288

2. Nguyen DH, Boutouil M, Sebaibi N, Leleyter L, Baraud F (2013) Valorization of seashell by-products in pervious concrete pavers. Constr Build Mater 49:151-160

3. Vishwas PK, Sanjay KBG (2013) Comparative study on coconut shell aggregate with conventional concrete. Int J Eng Innov Technol 2(12):67-70

4. Milutienè E, Staniškis JK, Kručius A, Auguliene V, Ardickas D (2012) Increase in buildings sustainability by using renewable materials and energy. Clean Technol Environ Policy 14:1075-1084

5. Pelisser F, Zavarise N, Longo TA, Bernardin AM (2011) Concrete made with recycled tire rubber: effect of alkaline activation and silica fume addition. J Clean Prod 19(6):757-763

6. Ismail S, Ramli M (2013) Engineering properties of treated recycled concrete aggregate (RCA) for structural applications. Constr Build Mater 44:464-476

7. Okpala DC (1990) Palm kernel shell as a lightweight aggregate in concrete. Build Environ 25(4):291-296

8. Pantzaris TP, Ahmad MJ (2001) Properties and utilization of palm kernel oil. In: Hertford (ed). Malaysian palm oil board (Europe), Brickendonbury

9. Olanipekun EA, Olusola KO, Ata O (2006) A comparative study of concrete properties using coconut shell and palm kernel shell as coarse aggregates. Build Environ 41(3):297-301

10. Teo DCL, Mannan MA, Kurian JV (2006) Flexural behaviour of reinforced lightweight concrete beams made with oil palm shell (OPS). J Adv Concr Technol 4(3):1-10

11. Ramli A (2003) Short-term and long-term projection of Malaysian palm oil production (MPOB). Oil Palm Ind Econ J 3(1):33-36

12. Mannan MA, Ganapathy C (2002) Engineering properties of concrete with oil palm shell as coarse aggregate. Constr Build Mater 16(1):29-34

13. Basri HB, Mannan MA, Zain MFM (1999) Concrete using waste oil palm shells as aggregate. Cem Concr Res 29(4):619-622

14. Abdullah AAA (1997) Palm oil shell aggregate for lightweight concrete. In: Chandra S (ed) Waste material used in concrete manufacturing, chap 10. Noyes Publication, New York

15. Teo DCL, Mannan MA, Kurian VJ (2006) Structural concrete using oil palm shell (OPS) as lightweight aggregate, Turkish. J Eng Environ Sci 30:1-7

16. Jusoh A, Noor MJMM, Ghazali AH (1995) Potential of burnt palm shell (BOPS) granules in deep bed filtration. J Islam Acad Sci 8(3):143-148 
17. Amu OO, Haastrup AO, Eboru AA (2008) Effects of palm kernel shells in lateritic soil for asphalt stabilization. Res J Environ Sci 2(2):132-138

18. Mohamed $\mathrm{G}$ et al (2017) Structural mixture proportioning for oil palm shell concrete. Case Stud Constr Mater 6:219-224

19. Yusuf IT, Babatunde YO, Abdullah A (2018) Investigation on flexural strength of palm kernel shell concrete for structural application. Malays J Civ Eng 30(2):268-281

20. Elnaz K et al (2017) Comparing the effects of oil palm kernel shell and cockle shell on properties of pervious concrete pavement. Int J Pavement Res Technol 10(5):383-392

21. Mohammad $M$ et al (2016) Mechanical and fresh properties of sustainable oil palm shell lightweight concrete incorporating palm oil fuel ash. J Clean Prod 115(1):307-314

22. Elnaz K et al (2016) Properties of sustainable lightweight pervious concrete containing oil palm kernel shell as coarse aggregate. Constr Build Mater 126:1054-1065

23. Oyedepo OJ, Olanitori LM, Akande SP (2015) Performance of coconut shell ash and palm kernel shell ash as partial replacement for cement in concrete. J Build Mater Struct 2:18-24

24. Okechukwu PO, Kevin NN, Ngozi AAO (2017) Assessment of palm kernel shell as a composite aggregate in concrete. Agric Eng Int CIGR J 19(2):34-41

25. Ali AAA (1984) Basic strength properties of lightweight concrete using agricultural wastes as aggregates in low-cost housing for developing countries. Roorkee, India

26. BS EN 197-1 (2000) Cement composition, specifications and conformity criteria for common cements

27. BS EN 12390-4 (2000) Testing hardened concrete. Compressive Strength

28. Gunasekaran K, Annadurai R, Kumar PS (2012) Long term study on compressive and bond strength of coconut shell aggregate concrete. Constr Build Mater 28:20815-20861

29. BS EN 1097-3:1998 Testing aggregates. Method for determination of density

30. Ndoke PN (2006) Performance of palm kernel shells as a partial replacement for coarse aggregate in asphalt concrete. Leonardo El J Pract Technol 5(9):145-152

31. Mannan MA, Ganapathy C (2001) Long-term strengths of concrete with oil palm shell as coarse aggregate. Cem Concr Res 31(9):1319-1321
32. Hemmings RT, Cornelius BJ, Yuran P, Wu M (2009) Comparative study of lightweight aggregates. In: 2009 world of coal ash (WOCA) conference 2009. Lexington, KY, USA

33. BS812-103.1: 2003, Testing aggregate particle distribution

34. Basheer L, Kropp J, Cleland DJ (2001) Assessment of the durability of concrete from its permeation properties: a review. Constr Build Mater 15(2-3):93-103

35. Neville AM (1995) Properties of concrete. Wiley, Harlow

36. Short A, Kinniburgh W (1978) Lightweight concrete. Applied Science Publishers, London

37. Gunasekaran K, Kumar PS, Lakshmipathy M (2011) Mechanical and bond properties of coconut shell concrete. Constr Build Mater 25(1):92-98

38. Hossain A, Khandaker M (2004) Properties of volcanic pumice based cement and lightweight concrete. Cem Concr Res 34(2):283-291

39. Alengaram UJ, Mahmud H, Jumaat MZ, Shirazi SM (2010) Effect of aggregate size and proportion on strength properties of palm kernel shell concrete. Int J Phys Sci 5(12):1848-1856

40. ACl116R (2000) Cement and concrete terminology

41. Gunasekaran K, Annadurai R, Kumar PS (2013) Study on reinforced lightweight coconut shell concrete beam behavior under flexure. Mater Des 46:157-167

42. Clarke DJL (1993) Structural lightweight aggregate concrete. Routledge, London

43. Yerramala A, Ramachandrudu C (2012) Properties of concrete with coconut shells as aggregate replacement. Int J Eng Invent 1(6):21-31

44. Daniel YO (2013) Experimental assessment on coconut shell as aggregate in concrete. Int J Eng Sci Invent 2(5):07-11

45. Alengaram UJ, Mahmud H, Jumaat MZ (2011) Enhancement and prediction of modulus of elasticity of palm kernel shell concrete. Mater Des 32(4):2143-2148

Publisher's Note Springer Nature remains neutral with regard to jurisdictional claims in published maps and institutional affiliations. 